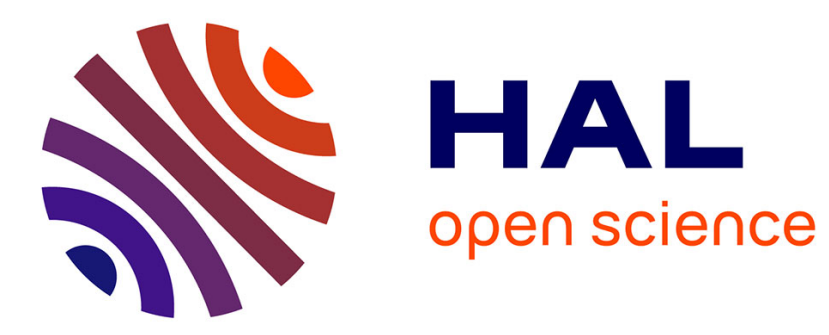

\title{
Neoadjuvant chemoradiotherapy with capecitabine followed by laparoscopic resection in locally advanced tumors of middle and low rectum-toxicity and complications of the treatment
}

R. Soumarova, M. Skrovina, J. Bartos, J. Gruna, A. Wendrinski, S. Czudek, R. Kycina, J. Parvez

\section{To cite this version:}

R. Soumarova, M. Skrovina, J. Bartos, J. Gruna, A. Wendrinski, et al.. Neoadjuvant chemoradiotherapy with capecitabine followed by laparoscopic resection in locally advanced tumors of middle and low rectum-toxicity and complications of the treatment. EJSO - European Journal of Surgical Oncology, 2010, 36 (3), pp.251. 10.1016/j.ejso.2009.10.002 . hal-00566746

\author{
HAL Id: hal-00566746 \\ https://hal.science/hal-00566746
}

Submitted on 17 Feb 2011

HAL is a multi-disciplinary open access archive for the deposit and dissemination of scientific research documents, whether they are published or not. The documents may come from teaching and research institutions in France or abroad, or from public or private research centers.
L'archive ouverte pluridisciplinaire HAL, est destinée au dépôt et à la diffusion de documents scientifiques de niveau recherche, publiés ou non, émanant des établissements d'enseignement et de recherche français ou étrangers, des laboratoires publics ou privés. 


\section{Accepted Manuscript}

Title: Neoadjuvant chemoradiotherapy with capecitabine followed by laparoscopic resection in locally advanced tumors of middle and low rectum-toxicity and complications of the treatment

Authors: R. Soumarova, M. Skrovina, J. Bartos, J. Gruna, A. Wendrinski, S. Czudek,

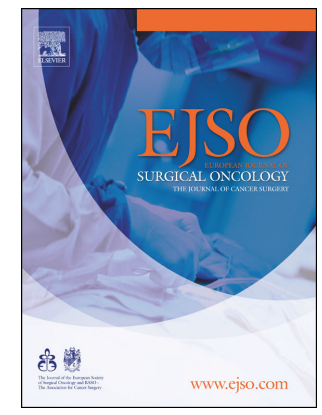
R. Kycina, J. Parvez

PII: S0748-7983(09)00471-5

DOI: 10.1016/j.ejso.2009.10.002

Reference: $\quad$ YEJSO 2896

To appear in: European Journal of Surgical Oncology

Received Date: 25 January 2009

Revised Date: 21 September 2009

Accepted Date: 1 October 2009

Please cite this article as: Soumarova R, Skrovina M, Bartos J, Gruna J, Wendrinski A, Czudek S, Kycina R, Parvez J. Neoadjuvant chemoradiotherapy with capecitabine followed by laparoscopic resection in locally advanced tumors of middle and low rectum-toxicity and complications of the treatment, European Journal of Surgical Oncology (2009), doi: 10.1016/j.ejso.2009.10.002

This is a PDF file of an unedited manuscript that has been accepted for publication. As a service to our customers we are providing this early version of the manuscript. The manuscript will undergo copyediting, typesetting, and review of the resulting proof before it is published in its final form. Please note that during the production process errors may be discovered which could affect the content, and all legal disclaimers that apply to the journal pertain. 
Neoadjuvant chemoradiotherapy with capecitabine followed by laparoscopic resection in locally advanced tumors of middle and low rectum - toxicity and complications of the treatment.

Soumarova $\mathrm{R}^{\mathrm{a}}$, Skrovina $\mathrm{M}^{\mathrm{b}}$, Bartos $\mathrm{J}^{\mathrm{b}}$, Gruna $\mathrm{J}^{\mathrm{a}}$, Wendrinski $\mathrm{A}^{\mathrm{b}}$, Czudek $\mathrm{S}^{\mathrm{b}}$, Kycina $\mathrm{R}^{\mathrm{b}, \mathrm{c}}$, Parvez J

${ }^{\mathrm{a}}$ Department of Radiotherapy and Oncology, J. G. Mendel Cancer Center Novy Jicin, Czech Republic

${ }^{\mathrm{b}}$ Department of Surgery, J. G. Mendel Cancer Center Novy Jicin, Czech Republic

'Surgical Clinic of Martin Faculty Hospital, Jessenius Medical Faculty of Commenius University, Martin, Slovakia

Address for correspondence:

Renata Soumarova, M.D., Ass. Prof., PhD.

e-mail: renata.soumarova@radioterapie.cz

J. G. Mendel Cancer Center Novy Jicin

Purkynova 2138/16

Novy Jicin, 74101

Czech Republic

Telephone: +420 556794180 


\section{Abstract}

\section{Aims:}

The aim of this prospective study is to elucidate feasibility of protocol of neodjuvant concomitant radio chemotherapy with capecitabine and long course radiotherapy with subsequent laparoscopic rectal resection. We assessed treatment toxicity, downstaging rate, pathological response to the neoadjuvant treatment, surgery complications, rate of conversions and sphincter-preserving surgical procedures, and intraoperative and early postoperative complications too.

Methods:

We acquired data of 78 patients from 1 January 2005 to 31 December 2007 with a locally advanced rectal cancer in our study. All patients were indicated for the neoadjuvant concomitant chemoradiotherapy due to locally advanced tumor (T3 or T4) or lymph nodes involvement suspicion $(\mathrm{N}+)$. Both radiotherapy (to pelvic region) and chemotherapy (capecitabine) were administered. Rectal tumors were localized within $12 \mathrm{~cm}$ from the anocutaneous verge. The average follow-up time was 23.9 months.

Results:

All patients completed their treatment according to the planned regimen and dose. The surgery was performed laparoscopicaly within 4-8 weeks following the concomitant chemoradiotherapy - in 17\% cases was converted into conventional surgery. Downstaging was achieved in $69 \%$ of patients, pathological complete response in $10 \%$, histologically negative lymph nodes were documented in $58 \%$ of patients. Grade 3 toxicity of the concomitant chemoradiotherapy was present in 3\%; grade 2 in $29 \%$ of patients, particularly skin and gastrointestinal form. Intraoperative and early postoperative complications of the surgery were $18 \%$. Reoperation was needed in $5 \%$ cases. 


\section{Conclusions:}

We demonstrated safety and low toxicity of the concomitant chemoradiotherapy with capecitabine.

\section{Key words}

Rectal cancer - Laparoscopy - Neoadjuvant concomitant chemoradiotherapy - Capecitabine - Treatment toxicity 


\section{Introduction}

Curative radical surgery is essential treatment of the localized rectal tumors. In the locally advanced tumors (T3, $\mathrm{T} 4$ or $\mathrm{N}+$ ) the surgery is combined with preoperative radiotherapy (RT), which leads to better local control of the disease and to improved survival compared with surgery alone $(1,2)$. Randomized trials have demonstrated, that the outcomes of concomitant chemoradiotherapy (CHT/RT) are superior to the radiotherapy alone (3). The EORTC phase III trial compared radiotherapy alone with radiotherapy combined with chemotherapy (CHT) consisting of administration of 5-fluorouracil and leucovorine (FUFA) as a bolus in weeks 1 and 5. In the CHT arm was the rate of pathological complete response significantly higher; it is very important for the prognosis of the patient (4).

The primary endpoint of the neoadjuvant concomitant chemoradiotherapy is overall survival improvement but an important secondary aim is to reduce the size of the tumor (downstaging) but to improve the local disease control too. Highly discussed benefit of this treatment is the increasing of sphincter-preserving surgeries in more distally located tumors too. In some trials this benefit was statistically significant; in other trials it was not confirmed. Major German trial (CAO/ARO/AIO-94) compared the use of concomitant CHT/RT before the surgery and after the surgery (5). Sphincter-preserving surgery following preoperative administration was successfully performed in 39\% vs. $19 \%$ in after CHT/RT surgery group, late stenosis of the anastomosis occurred in 3\% vs. 9\%, local recurrence occurred in 7\% vs. 11\%. Grade 3 and 4 acute toxicity was lower in neoadjuvant concomitant CHT/RT group (27\% vs. 40\%), late toxicity too (14\% vs. $24 \%)$. However, distant dissemination was comparable in both arms (34\% vs. $36 \%$ ) as well as overall survival (76\% vs. $74 \%$ ).

Continual administration of 5- fluorouracil is more favorable over the bolus administration as for the toxicity, but the handicap is a need of hospitalization and central venous catheter insertion, both with negative influence on the quality of life of the oncological patients (6). 
Capecitabine (Xeloda; Hoffmann-LaRoche, Inc., Nutley, NJ) imitates the continual administration of 5-FU. According to phase I study the recommended capecitabine dose 825 $\mathrm{mg} / \mathrm{m}^{2}$ administering twice daily was determined for concomitant administration with radiotherapy (7). Phase II studies have confirmed good tolerance and efficacy in patients with locally advanced rectal cancer (8). Convenient safety profile of capecitabine has been recently demonstrated in randomized phase III trials in comparison with bolus FUFA; the preference of oral form of chemotherapy by patients too (9)

Diarrhea, local skin reactions and hand-foot syndrome are the most common side effects of concomitant chemoradiotherapy with capecitabine.

Continual administration of 5-fluoruracil or oral administration of capecitabine during all the time of radiotherapy are standard concomitant neoadjuvant CHT/RT treatment in local advanced rectal cancer now.

Laparoscopic surgery is alternative to the open surgical procedure which comply all criteria for oncological radicality $(10,11)$.

\section{Material and methods}

All patients were completely examined and underwent all staging procedures, including CT, transrectal sonography and MRI. Blood analysis, including tumor marker analysis was performed as a standard part of the examination. Tumors were histologically verified before the treatment in all cases. We discussed the indication for neoadjuvant chemoradiotherapy case to case in everyone patient at the multidisciplinary hospital committee, consisting of surgeons, gastroenterologists, imaging specialists, radiotherapists and clinical oncologists.

The neoadjuvant chemoradiotherapy was indicated to patients in good general status (ECOG - Eastern Cooperative Oncology Group - performance status $\leq$ 2) with histologically verified adenocarcinoma. According to the initial transrectal ultrasound examination and pelvic CT scan respectively, tumors were classified as $\mathrm{T} 3$ or $\mathrm{T} 4$ or $\mathrm{N}+$ (TNM classification) (12). 
Patients who had lower or middle rectal tumors within $12 \mathrm{~cm}$ from anocutaneous verge, were prospectively enrolled into our study.

Radiotherapy (RT) was performed by a linear accelerator to the pelvic region in the dose of 45.0-50,4 Gy in 25-28 fractions given within 5-5.5 weeks. 3- or 4-field method with multileaf collimator was used (three-dimensional - 3D conform RT). Simultaneously with the radiotherapy, capecitabine in the dose of $825 \mathrm{mg} / \mathrm{m}^{2}$ twice daily was given all time long (5 weeks). All patients completed the scheduled treatment. Toxicity of the neoadjuvant chemoradiotherapy was assessed according to the EORTC/RTOG criteria.

Within 4 to 8 weeks from the completion of the neoadjuvant chemoradiotherapy the patients underwent the surgery. The surgery was carried out in a single hospital by a single team. Follow-up CT and TRUS were performed close before the surgery. The procedure was initiated in laparoscopic way in all cases. Both total mesorectal excision (TME) and abdominoperineal amputation (APR) were carried out by "nerves sparing surgery” method. We performed colonic lienal flexure deliberation in most patients with low anterior resection (LAR). All events leading to surgical tactic modification and iatrogenic lesion treatment outside the planned resection extent were assessed as intraoperative complications. All surgical and non-surgical complications reported until day 30 after surgery we considered as early postoperative complications.

\section{Statistics}

We used the Fischer exact test to test the difference between groups according to gender. The Mann-Whitney U test was used to compare the age, surgery duration, postoperative hospital stay, distance between the tumor and anocutaneous verge and number of lymph nodes assessed. The analysis was performed by software SPSS (SPSS Inc, Chicago IL) and SAS 
(SAS Institute, Cary NC). Significance level below 0.05 was considered statistically significant.

\section{Results}

Patients

From January 2005 to December 2007 we treated 78 patients, 62 men and 16 women. Average follow-up was 23.9 months, median 24 (7-39). Average age was 62 years, median 62.8 years $(27-84)$. Most of patients had tumor assessed as T3 (72 \%). All tumors were located within $12 \mathrm{~cm}$ from the anocutaneous verge; median distance was $6 \mathrm{~cm}$. Stratification of patients according to the TMN classification is in Table 1.

Toxicity of the neoadjuvant therapy

The toxicity of the neoadjuvant chemoradiotherapy was assessed according to the EORTC/RTOG criteria. No patient had grade 4 toxicity, grade 3 toxicity occurred in 2 patients only - both were hematological (neutropenia). Grade 2 toxicity had 23 patients - 10 had gastrointestinal, 9 had dermatologic and 2 genitourinary symptoms. Hand foot syndrome did not occur in any patient.

Type of surgical procedure

Sphincter-preserving surgery was possible to carry out in $47 \%$ of cases only, but patients with abdominoperineal amputation (APR) had significantly more caudally located tumor ( $5 \mathrm{~cm}$ vs. $7 \mathrm{~cm}, \mathrm{p}=0,01)$. Patients with abdominoperineal amputation were significantly older too $(\mathrm{p}=0,01)$. Groups were comparable according to hospital stay, time of surgery and number of assessed lymph nodes (Table 2).

We had to carry out conversion of laparoscopy into open surgery in 13 cases. It was caused by tumor size in 9 of them.

Surgical complications 
Intraoperative complications we had in 4 patients. The urethral lesion required conversion of laparoscopic resection to an open surgery. All other intraoperative complications (small rectal lesion, small urinary bladder lesion and stapler failure) were solved by laparoscopic approach and no further complications were recorded in time of the postoperative period.

Average hospital stay was 10 days. No patients died due to treatment complications. Surgical postoperative complications (until day 30) occurred in 7 cases. Anastomotic leak we had in 4 cases from 37 patients after low anterior resection of rectum, but in 2 patients re-operation was needed only. 4 patients had to undergo re-operation during the early postoperative period. Non surgical complications we had in 3 cases -1 pneumonia, 1 urinary retention and 1 paresis of brachial nerve.

Response to the treatment

Downstaging was achieved in 54 patients (Table 1). 58\% patients with advanced rectal carcinoma had pathologically negative lymph nodes after neoadjuvant CHT/RT. From all patents in the group almost $25 \%$ were initially as T4 stage according to the transrectal sonography (TRUS) and CT, only in 2 patients the subsequent pathological classification was ypT4. Pathological complete response was reported in 8 patients. All patients underwent radical surgery.

\section{Discussion}

\section{Neoadjuvant concomitant chemoradiotherapy}

Neoadjuvant concomitant chemoradiotherapy is standard part of the treatment of patients with the locally advanced rectal cancer in effort to downstaging achievement, improved tumor operability, improved local disease control and the most important - overall survival. Downstaging was achieved in our work in $69 \%$ patients. Pathological complete response we 
achieved in $10 \%$. These data are comparable to other cohorts in the literature. Outcomes of the phase II trials of concomitant chemoradiotherapy with capecitabine are in Table 3 (1321).

Slovenian study reported pathological complete response in $9 \%$ in cohort of 57 patients; downstaging they achieved in 49\% (16). Toxicity and efficacy was assessed in the Greek study in group of 30 patients (17). In their work downstaging was in 75\% patients, pathological complete response was high - in $23 \%$ of them. In comparison to our cohort, $17 \%$ patients with T4 tumor were enrolled into this trial, while almost 25\% patients in T4 stage were enrolled into our cohort, but only in 2 cases the disease was subsequently classified as ypT4. Grade 3 toxicity was seen in $10 \%$ of patients (leucopenia), in our cohort it is $3 \%$ only. Intraoperative and early postoperative complications were similar - 20\%.

\section{Side effects}

Capecitabine is radiosensitizer with different toxicity profile than continual or bolus administration of 5-fluorouracil. Administration of capecitabine can lead into side effects hematologic (leucopenia, thrombocytopenia, anemia) or non-hematologic (fatigue, stomatitis, nausea, vomiting, diarrhea, dermatitis, hand-foot syndrome). The most common complication of simultaneous administration of capecitabine and radiotherapy is acute gastrointestinal toxicity. It is 12 - 34\% in grade 2 and 3 toxicity (18). It is similar to our results.

Low presence of hand-foot syndrom is, in our opinion, caused by relatively short time of administration of capecitabine. Most studies, where this syndrome is recorded, are carried out in patients with metastatic disease when the time of administration is longer.

Hematological toxicity of grade 3 and 4 is low too, in comparison to bolus or continual administration of fluorouracil (9). 
Low presence of grade 3 adverse effects, similar to our results, was reported in a paper of Dutch authors, the same percentage - 3\% only in 60 cured patients (21). Pathological complete response was reported in $13 \%$. Another Slovenian study reported pathological complete response in 9\% in 57 patients; downstaging they achieved in $49 \%$ (16).

Neodjuvant concomitant chemoradiotherapy was well tolerated in our patients and there was no reason to interrupt the treatment. Pathological response is a proven factor influencing overall survival; therefore there are efforts to achieve the highest response rate possible without an unacceptable toxicity increase (22).

\section{Pathological N stage}

The pathological $\mathrm{N}$ stage is very important prognostic factor for overall survival too. In our paper almost $60 \%$ of patients had negative lymph nodes, in the Craven's study the figure was similar (19). Lymph nodes were originally assessed positive in 49 patients (63\%). But we have to realize, that an exact method for determining preoperative positivity of lymph nodes does not exist.

Radical lymphonodectomy belongs to criteria of oncological radicality too. Quantity of lymph nodes removed is determined by several factors. The first factor is the patient alone, according to his anatomic circumstances what determines the quantity of lymph nodes in the resected region. The second factor is the surgeon alone, who can by the surgical method, technique, experience and the extent of resection significantly influence the quantity of lymph nodes. The third factor is the pathologist by his way of specimen processing and by the precision of the assessment determines $\mathrm{pN}$ component of the TMN classification of the colorectal cancer. The number of examined lymph nodes is usually lower following the neoadjuvant therapy (23), in our cohort it was 14-18 lymph nodes in average. This finding we can confirm in our 
cohort of patients operated without the neoadjuvant therapy by the same team of surgeons, where the average number of examined lymph nodes was 24.9 (24).

\section{Anastomotic leak}

One of the most severe surgical complications is the anastomotic leak following the lower rectal resection with total mesorectal excision, which is reported from $1 \%$ to $24 \%$. The anastomotic leak was seen in $11 \%$ of cases in our cohort of patients operated by the sphincterpreserving approach following the pre-surgical chemoradiotherapy. It was necessary to treat the symptomatic dehiscence of the anastomosis by re-operation in $5 \%$ only. Sauer et al. from the German Rectal Cancer Study Group report in their multicentre randomized study postoperative complication in $36 \%$ patients following the preoperative chemoradiotherapy compared to $34 \%$ of postoperative complications in a cohort of patients operated primarily with the intention of postoperative chemoradiotherapy $(p=0.68)$. They report the leak of anastomosis in $12 \%$ of patients following the preoperative chemoradiotherapy compared to $11 \%$ patients treated by primary surgery $(\mathrm{p}=0.77)$. In the group of preoperative chemoradiotherapy the mortality was $0.7 \%$ vs. $1,3 \%$ in the other group $(p=0,41)(25)$. The mortality was $0 \%$ in our cohort.

In the randomized multicentre trial published by Swedish authors RECTODES (REctal Cancer Trial On DEfunctioning Stoma) the outcomes of patients with rectal cancer within $\leq$ $15 \mathrm{~cm}$ from the anal verge with or without primarily established protective ileostomy were reviewed. The presence of the symptomatic leak was reported in $19 \%$ of cases, in patients with protective ileostomy in $10 \%$, without the primarily established ileostomy in $28 \%$. Urgent re-operation was necessary in $9 \%$ of patients with stoma and in $25 \%$ of patients operated without protective ileostomy (26). 
The trials with preoperative concomitant chemoradiotherapy with 5-fluorouracil (5-FU) led into local disease control improvement, to the tumor downstaging, but with no difference in disease dissemination and overall survival. This is the argument for searching of new cytostatic agents or their new combinations. Capecitabine is one of them. The low toxicity and achieved pathological responses raises the question, whether the combination with other cytostatic agents could improve the rate of pathological complete response and thus also overall survival in the group of patients with locally advanced disease. Several phase I and II trials have been published, especially the combinations of capecitabine with irinotecane and oxaliplatin. The pathological complete response is usually more than $20 \%$ (27-30), but the toxicity of the treatment is higher.

\section{Conclusion}

The aim of the preoperative chemoradiotherapy is, but overall survival, to achieve downstaging of the tumor and to improve operability with eventually increased rate of the sphincter-preserving operations. However, this therapy should not be burdened by increased number of severe complications. We have demonstrated very good tolerability and efficacy of the concomitant chemoradiotherapy with capecitabine in our work, which can replace the continual administration of 5-fluorouracil in this indication. We have also demonstrated suitability and low rate of complication of the subsequent laparoscopic operation. The pathological complete response is by this approach according to the literature 9-20\%, results probably could be improved by adding another cytostatic agent.

We did not register any direct relation between toxicity of capecitabine and laparoscopic surgery.

Proclamation: 
All authors proclaim no financial and personal relationships with other people or organizations that could inappropriately influence their work. 


\section{References}

1. Camma C, Giunta M, Fiorica F, et al. Preoperative radiotherapy for resectable rectal cancer: A meta-analysis. JAMA 2000;284:1008-15.

2. Glimelius B, Isacsson U, Jung B, et al. Radiotherapy in addition to radical surgery in rectal cancer: Evidence for a dose-response effect favoring preoperative treatment. Int J Radiat Oncol Biol Phys 1997;37:281-7.

3. Rodel C, Grabenbauer GG, Schick C, et al. Preoperative radiation with concurrent 5fluorouracil for locally advanced T4-primary rectal cancer. Strahlenther Onkol 2000; 176(4):161-7.

4. Bosset JF, Calais G, Mineur L, et al. Enhanced tumorocidal effect of chemotherapy with preoperative radiotherapy for rectal cancer: preliminary results-EORTC 22921. J Clin Oncol 2005,20;23(24):5620-7.

5. Sauer R, Becker H, Hohenberger W, et al. German Rectal Cancer Study Group, Preoperative versus postoperative chemoradiotherapy for rectal cancer. N Engl J Med 2004;351:1731-40.

6. Rich TA, Skibber JM, Ajani JA, et al. Preoperative infusional chemoradiation therapy for stage T3 rectal cancer. Int J Radiat Oncol Biol Phys 1995,32:1025-29.

7. Ngan SY, Michael M, Mackay J, et al. A phase I trial of preoperative radiotherapy and capecitabine for locally advanced, potentially resectable rectal cancer. Br J Cancer 2004;91:1019-24.

8. Dupuis O. Capecitabine (X) chemoradiation (CRT) in the preoperative treatment of patients (pts) with rectal adenocarcinomas: a phase II GERCOR trial. Abstract 3538. Proc Am J Clin Oncol 2004;23:255.

9. Hoff PM, Ansari R, Batist G, et al. Comparison of oral capecitabine versus intravenous fluorouracil plus leucovorin as first-line treatment in 605 patients with 
metastatic colorectal cancer: results of a randomized phase III study. J Clin Oncol 2001;19:2282-92.

10. Feliciotti F, Paganini AM, Guerrieri M, et al. Results of laparoscopic vs open resections for colon cancer in patients with a minimum follow-up of 3 years. Surg Endosc 2002,16,1158-61.

11. Jacob BP, Salky B. Laparoscopic colectomy for colon adenocarcinoma. Surg Endosc 2005,19:643-49.

12. International Union Against Cancer (UICC), TNM klasifikace zhoubnych novotvaru, Seste vydani 2002, Ustav zdravotnickych informaci a statistiky Ceske republiky, Praha, 2004,65-68, ISBN 80-7280-391-3.

13. Dupuis O. Capecitabine (X) chemoradiation (CRT) in the preoperative treatment of patients (pts) with rectal adenocarcinomas: a phase II GERCOR trial. Abstract 3538. Proc Am J Clin Oncol 2004;23:255.

14. Wong SJ, Sadasiwan C, Erickson B, et al. A phase II trial of preoperative capecitabine and concurrent radiation for locally advanced rectal cancer Abstract 281. Proc Am Soc Clin Oncol Gastrointest Cancer Symp 2004.

15. Krishnan S, Janjan NA, Skibber JM, et al. Phase II study of capecitabine (Xeloda) and concomitant boost radiotherapy in patients with locally advanced rectal cancer. Int J Radiat Oncol Biol Phys 2006;66:762-71.

16. Velenik V, Anderluh F, Oblak I, et al. Capecitabine as a radiosensitizing agent in neoadjuvant treatment of locally advanced resectable rectal cancer: prospective phase II trial. Croat Med J 2006;47:693-700.

17. Korkolis DP, Boskos CS, Plataniotis GD, et al. Pre-operative chemoradiotherapy with oral capecitabine in locally advanced, resectable rectal cancer. Anticancer Res 2007;27(1B):541-5. 
18. Kim JCh, Kim TW, Kim JH, et al. Preoperative concurrent radiotherapy with capecitabine before total mesorectal excision in locally advanced rectal cancer. Int $\mathrm{J}$ Radiat Oncol Biol Phys 2005;63(2):346-53.

19. Craven I, Crellin A, Cooper R, et al. Preoperative radiotherapy combined with 5 days per week capecitabine chemotherapy in locally advanced rectal cancer. Br J Cancer 2007;97(10):1333-7.

20. Kocakova I, Svoboda M, Kubosova K, et al. Preoperative radiotherapy and concomitant capecitabine treatment induce thymidylate synthase and thymidine phosphorylase mRNAs in rectal carcinoma. Neoplasma 2007;54(5):447-53.

21. de Bruin AF, Nuyttens JJ, Ferenschild FT, et al. Preoperative chemoradiation with capecitabine in locally advanced rectal cancer. Neth J Med 2008;66(2):71-6.

22. Rosenberg R, Nekarda H, Zimmermann F, et al. Histopathological response after preoperative radiochemotherapy in rectal carcinoma is associated with improved overall survival. J Surg Oncol 2008,1;97(1):8-13.

23. Wichmann MW, Muller C, Meyer G, et al. Effect of preoperative radiochemotherapy on lymph node retrieval after resection of rectal cancer. Arch Surg 2002,137:206-10.

24. Skrovina M, Bartos J, Soumarova R, et al. Laparocopic Resection of rectal cancer: evaluation of perioperative results of the primary resection and resection after preoperative chemoradiotherapy. Rozhl Chir 2008,87:417-25.

25. Sauer R, Becker H, Hohenberger W, at al. German Rectal Cancer Study Group, Preoperative versus postoperative chemoradiotherapy for rectal cancer. N Engl J Med 2004,351:1731-40.

26. Matthiessen, P., Hallbook, O., Rutegard, J., et al. Defunctioning stoma reduces symptomatic anastomotic leakage after low anterior resection of the rectum for cancer, a randomized multicenter trial. Ann Surg 2007,246:207-14. 
27. Klautke G, Kuchenmeister U, Foitzik T, et al. Concurrent chemoradiation with capecitabine and weekly irinotecan as preoperative treatment for rectal cancer: results from a phase I/II study. Br J Cancer 2006;94:976-81.

28. Chau I, Brown G, Cunningham D, et al. Neoadjuvant capecitabine and oxaliplatin followed by synchronous chemoradiation and total mesorectal excision in magnetic resonance imaging-defined poor-risk rectal cancer. J Clin Oncol 2006;24:668-74.

29. Machiels JP, Duck L, Honhon B, et al. Phase II study of preoperative oxaliplatin, capecitabine and external beam radiotherapy in patients with rectal cancer: the RadiOxCape study. Ann Oncol 2005;16:1898-905.

30. Rodel C, Grabenbauer GG, Papadopoulos T, et al. Phase I/II trial of capecitabine, oxaliplatin, and radiation for rectal cancer. J Clin Oncol 2003;21:3098-104. 
Table 1

Stratification according to the TNM and ypTN classification

\begin{tabular}{|c|c|c|c|c|c|}
\hline $\begin{array}{c}\text { Clinical } \\
\text { staging }\end{array}$ & Number & Rate & $\begin{array}{c}\text { Pathological } \\
\text { classification ypTN }\end{array}$ & Number & Rate \\
\hline T1 & 0 & $0 \%$ & ypT0 & 8 & $10 \%$ \\
\hline T2 & 3 & $4 \%$ & ypT1 & 3 & $4 \%$ \\
\hline T3 & 56 & $72 \%$ & ypT2 & 25 & $32 \%$ \\
\hline T4 & 19 & $24 \%$ & ypT3 & 40 & $51 \%$ \\
\hline N0 & 24 & $31 \%$ & ypT4 & 2 & $3 \%$ \\
\hline N+ & 49 & $63 \%$ & pN0 & 45 & $58 \%$ \\
\hline NX & 5 & $6 \%$ & pNX & 3 & $4 \%$ \\
\hline
\end{tabular}


Table 2

Comparison of the patient cohort according to the surgical procedure

\begin{tabular}{|c|c|c|c|}
\hline & LAR & APR & $P$ value \\
\hline Number of patients & 37 & 41 & \\
\hline Men & 27 & 35 & \multirow{2}{*}{0.29} \\
\hline Women & 10 & 6 & \\
\hline $\begin{array}{l}\text { Age - } \begin{array}{l}\text { median }+ \text { SD } \\
\text { range } \\
\text { average }\end{array} \\
\end{array}$ & $\begin{array}{c}59 \pm 7 \\
39-74 \\
59\end{array}$ & $\begin{array}{c}65 \pm 9 \\
27-84 \\
64\end{array}$ & 0.01 \\
\hline $\begin{array}{c}\text { Distance } \mathrm{T}-\mathrm{ACV}-\text { median }+\mathrm{SD} \\
\text { range } \\
\text { average }\end{array}$ & $\begin{array}{c}70 \pm 23 \\
30-120 \\
71\end{array}$ & $\begin{array}{c}50 \pm 28 \\
20-120 \\
54\end{array}$ & 0.01 \\
\hline $\begin{array}{c}\text { Hospital stay - } \\
\text { median }+\mathrm{SD} \\
\text { range } \\
\text { average }\end{array}$ & $\begin{array}{c}8 \pm 8 \\
5-51 \\
11\end{array}$ & $\begin{array}{c}9 \pm 5 \\
5-28 \\
10\end{array}$ & 0.21 \\
\hline $\begin{array}{c}\text { Duration of surgery - median + SD } \\
\text { range } \\
\text { average }\end{array}$ & $\begin{array}{c}240 \pm 56 \\
110-360 \\
240\end{array}$ & $\begin{array}{c}230 \pm 59 \\
70-380 \\
232 \\
\end{array}$ & 0,42 \\
\hline $\begin{array}{c}\text { Number LU }- \text { median }+\mathrm{SD} \\
\text { range } \\
\text { average }\end{array}$ & $\begin{array}{c}12 \pm 9 \\
0-38 \\
14\end{array}$ & $\begin{array}{l}16 \pm 12 \\
3-45 \\
19\end{array}$ & 0,06 \\
\hline
\end{tabular}

Distance T-ACV = Distance between the lowest tumor edge and anocutaneous verge 
Table 3

Results of trials with concomitant chemoradiotherapy with capecitabine

\begin{tabular}{|c|c|c|c|c|}
\hline Chemotherapy & Radiotherapy (Gy) & $\begin{array}{c}\text { Patients } \\
\text { (Number) } \\
\text { TN stages }\end{array}$ & $\begin{array}{c}\text { Pathological } \\
\text { CR }\end{array}$ & Reference \\
\hline $\begin{array}{l}\text { Capecitabine } 875 \\
\mathrm{mg} / \mathrm{m}^{2} \\
\text { BID }\end{array}$ & 45 Gy, (1.8 Gy/fr.) & $\begin{array}{l}51 \mathrm{pts} \\
\mathrm{T} 3, \mathrm{~T} 4 \text {, or } \\
\mathrm{N}+\end{array}$ & $\begin{array}{c}24 \%+12 \% \\
\text { nCR }\end{array}$ & 13 \\
\hline $\begin{array}{l}\text { Capecitabine } 875 \\
\mathrm{mg} / \mathrm{m}^{2} \\
\text { BID }\end{array}$ & 50.4 Gy (1.8 Gy/fr.) & $\begin{array}{c}18 \\
\mathrm{~T} 3, \mathrm{~T} 4 \text {, or } \\
\mathrm{N}+ \\
\end{array}$ & $\begin{array}{c}12 \%+12 \% \\
\text { nCR }\end{array}$ & 14 \\
\hline $\begin{array}{l}\text { Capecitabine } 825 \\
\mathrm{mg} / \mathrm{m}^{2} \\
\text { BID }\end{array}$ & 52.5 (30 fr.) & $\begin{array}{c}51 \\
\text { T3 or T3N1 }\end{array}$ & $18 \%$ & 15 \\
\hline $\begin{array}{l}\text { Capecitabine } 825 \\
\mathrm{mg} / \mathrm{m}^{2} \\
\text { BID }\end{array}$ & $\begin{array}{l}45 \text { Gy in } 25 \text { fr. In } 5 \\
\text { weeks }\end{array}$ & $\begin{array}{c}57 \text { pts } \\
\text { Resectable } \\
\text { stage II/III }\end{array}$ & $9 \%$ & 16 \\
\hline $\begin{array}{l}\text { Capecitabine } 825 \\
\mathrm{mg} / \mathrm{m}^{2} \\
\text { BID }\end{array}$ & $\begin{array}{l}50,4 \text { Gy in } 28 \text { fr. in 5,5 } \\
\text { weeks }\end{array}$ & $\begin{array}{l}30 \text { pts } \\
\text { T3, T4, or } \\
\text { N+ }\end{array}$ & $23 \%$ & 17 \\
\hline $\begin{array}{l}\text { Capecitabine } 1650 \\
\mathrm{mg} / \mathrm{m}^{2} \text { daily }\end{array}$ & $\begin{array}{l}46 \text { Gy in } 23 \text { fr. (pelvis) + } \\
4 \text { Gy ( } 2 \text { fr.) boost on } \\
\text { tumor }\end{array}$ & $\begin{array}{c}95 \text { pts } \\
\text { T3, T4, or } \mathbf{N} \\
+\end{array}$ & $12 \%$ & 18 \\
\hline $\begin{array}{l}\text { Capecitabine } 900 \\
\mathrm{mg} / \mathrm{m}^{2} \text { in } 5 \text { days of } \\
\mathrm{RT}\end{array}$ & $\begin{array}{l}45 \text { Gy in } 25 \text { fr. In } 5 \\
\text { weeks }\end{array}$ & $70 \mathrm{pts}$ & $\begin{array}{c}9 \% \\
\text { pN0 66\% }\end{array}$ & 19 \\
\hline $\begin{array}{l}\text { Capecitabine } 825 \\
\mathrm{mg} / \mathrm{m}^{2} \\
\text { BID }\end{array}$ & $\begin{array}{l}45 \text { Gy in } 25 \text { fr. in } 5 \\
\text { weeks (pelvis) + 5,4 Gy } \\
\text { ( } 3 \text { fr.) boost on tumor }\end{array}$ & $\begin{array}{c}55 \text { pts } \\
\text { T3, T4, or } \\
\mathrm{N}+ \\
\end{array}$ & $17 \%$ & 20 \\
\hline $\begin{array}{l}\text { Capecitabine } 825 \\
\mathrm{mg} / \mathrm{m}^{2} \\
\mathrm{BID} \text { in days of RT }\end{array}$ & $\begin{array}{l}50 \text { Gy in } 25 \text { fr. In } 5 \\
\text { weeks }\end{array}$ & $\begin{array}{c}60 \text { pts } \\
\text { T3, T4, or } \\
\mathrm{N}+ \\
\end{array}$ & $13 \%$ & 21 \\
\hline $\begin{array}{l}\text { Capecitabine } 825 \\
\mathrm{mg} / \mathrm{m}^{2} \\
\mathrm{BID}\end{array}$ & $\begin{array}{l}45.0-50.4 \text { Gy in } 25-28 \\
\text { fr. in 5-5,5 weeks }\end{array}$ & $\begin{array}{c}78 \text { pts } \\
\text { T3, T4, or } \\
\text { N+ }\end{array}$ & $\begin{array}{c}10 \% \\
\text { pN0 } 58 \%\end{array}$ & our study \\
\hline
\end{tabular}

BID - twice daily 